\title{
A feedback-feedforward suspension control strategy for global chassis control through anti-roll distribution
}

\section{Alessandro ZIN, Olivier SENAME and Luc DUGARD}

GIPSA-Lab, Departement of Control Systems, Grenoble Univer-
sités, ENSIEG - BP46, 38402 Saint Martin d'Hères - Cedex FRANCE

\{Olivier.Sename, Luc.Dugard\}@gipsa-lab.grenoble-inp.fr

\begin{abstract}
A new global chassis control strategy developed in two steps is proposed using the suspension actuators only. First, a robust $H_{\infty}$ Linear Parameter Varying (LPV) suspension controller is designed to ensure robust performance w.r.t parameter uncertainties. The interest of such a controller relies on its inherent structure which allows for performance adaptation through the variation of a scalar coefficient $c_{0}$. The second step consists in adding a feedforward compensator which controls the anti-roll distribution of the suspension forces to improve the vehicle safety in the presence of longitudinal and lateral disturbances. The control scheme consists in controlling the yaw rate through a model reference control. The global chassis control then relies on the adaptation of the suspension performance (comfort/safety), according to the anti-roll distribution. The interest of the methodology is emphasized through numerical simulations on a full vehicle non linear model, including chassis and tires.
\end{abstract}

Keywords: vehicle, active suspension, yaw control, anti-roll distribution, $H_{\infty}$, Linear Parameter Varying systems

\section{Biographical Notes:}

Alessandro Zin received the degree in mechanical engineering in 2002 from INSA Lyon, France, and a Ph.D. degree in Automatic control from the Grenoble Institut of Technology (Grenoble INP) in 2005, under the supervision of O.Sename and L.Dugard. He research topic concern vehcile dynamcis, in particular suspension control, using $H_{\infty}$ control approach. He is now working as an engineer, involved in control of automotive systems.

Olivier Sename received a Ph.D. degree in 1994 from the Ecole Centrale Nantes, France. He is now Professor at the Grenoble Institut of Technology (Grenoble INP), within the GIPSA-lab. His main research interests include theoretical studies in the field of time-delay systems and network-controlled systems (control of teleoperation systems with communication delays and integrated control/real-time scheduling codesign), as well as control applications of automotive vehicle suspensions, engine controls. He has collaborated with several industrial partners (Renault, SOBEN, Delphi Diesel Systems, Saint-Gobain Vetrotex, PSA, ST Microelectronics), and is Responsible of international bilateral re- 
search projects (Mexico, Hungary). He is the (co-)author of 6 book chapters, 20 international journal papers, and more than 80 international conference papers. He has supervised 15 Ph.D. students.

Luc Dugard works as a CNRS Senior Researcher (Directeur de Recherche CNRS) in the Automatic Control Dept. of GIPSA-lab, Grenoble, a research department of the Institut National Polytechnique de Grenoble, associated to the French research organism "Centre National de la Recherche Scientifique". Luc Dugard has published about 90 papers and/or chapters in international journals or books and more than 220 international conference papers. He has co advised $28 \mathrm{PhD}$ students. His main research interests include (or have included) theoretical studies in the field of adaptive control, robust control, time delay systems. The main control applications are oriented towards electromechanical systems, process control and automotive systems (suspensions, chassis and common rail systems).

\section{Introduction}

Over the past few years, automotive engineering has been characterized by rapid growth in active systems. In particular, efforts to improve driving safety and comfort under all driving conditions have been naturally focused on the chassis behavior. During the last decade, active control of vibration isolation in automotive vehicle has known a growing interest in research $[15,10,20]$. In particular the interest of the $H_{\infty}$ approach has been emphasized in the context of active suspension control of full vehicle models $[18,12,7]$.

However active safety and comfort are known to stumble over conflicting interests for the conventional chassis. To tackle this problem, the usual approach consists of an independent optimisation of the different chassis subsystems (in particular brakes, suspension actuators, steering, etc.). However, the complex and multivariable inherent nature of the vehicle makes such an approach inoperative. The target relies today on global chassis control [21] and on centralized control [23] strategies, to account for these coupling phenomena between steering, suspension and braking. In [25] the improvement in security is shown using steering and suspension actuators. In $[8,5,4]$ some control strategies using braking actuators, active anti-roll bars and/or active suspensions are developed in the LPV $/ H_{\infty}$ context for heavy vehicles. Finally in $[14,3,6,19]$ the collaboration between the braking and suspension actuators is investigated for vehicles, and in [2] for motorcycles..

In this paper a new feedback-feedforward global chassis control strategy is proposed based on suspension actuators only. First, a robust $H_{\infty}$ Linear Parameter Varying (LPV) suspension controller is designed to ensure robust performance w.r.t parameter uncertainties. The interest of such a controller also relies on its inherent structure which allows for performance adaptation through the variation of a scalar coefficient $c_{0}$. The second step consists in an original feedforward strategy which aims at limiting the sprung mass displacements in braking or acceleration phases, and, as well, at controlling the anti-roll distribution of the suspension forces to improve the vehicle safety in the presence of longitudinal and lateral disturbances. The control scheme for vehicle safety consists in controlling the yaw rate through 
a model reference PI controller. The global chassis control then relies on the adaptation of the suspension performance (comfort/safety) according to the anti-roll distribution. The interest of the methodology is emphasized through numerical simulations on a full vehicle non linear model including chassis and tires.

The outline of the paper is as follows. In section 2 , the full vehicle model is described. Then in section 3 the $\mathrm{LPV} / H_{\infty}$ feedback controller for active suspensions is developed. Section 4 is dedicated to the feed-forward strategy for global chassis control through anti-roll distribution. The paper ends with some concluding remarks.

\section{$2 \quad$ Vehicle modelling}

A full-car model is here described for the analysis of the dynamical car behavior, road holding and comfort. It is made of two subsystems representing the horizontal and vertical dynamics respectively, thereby extending the one developed in [24].

The main modelling assumptions are the use of rigid solids, neglection of longitudinal efforts, autoalignment tire moments, the kinematical effects due to the geometry of the suspensions, the gyroscopical effects on the suspended mass due to the yaw rate, the anti-roll bar effects and the aerodynamical effects. Moreover, the inertial axes of the suspended mass are assumed to cross each other at the center of gravity and are assumed to be parallel to the ground.

The horizontal model is then written as (cf figure 1) :

$$
\left\{\begin{aligned}
a_{x}(t)= & \dot{v}_{x}(t)-v_{y}(t) \dot{\psi}(t) \\
m a_{y}(t)= & m\left(\dot{v}_{y}(t)+v_{x}(t) \dot{\psi}(t)\right) \\
= & \left(F_{y t f r}(.)+F_{y t f l}(.)\right) \cos \left(\delta_{f}(t)\right) \\
& +F_{y t r r}(.)+F_{y t r l}(.)+F_{y d}(t), \\
I_{z} \ddot{\psi}(t)= & \left(F_{y t f r}(.)+F_{y t f l}(.)\right) \cos \left(\delta_{f}(t)\right) l_{f} \\
& -\left(F_{y t r r}(.)+F_{y t r l}(.)\right) l_{r}+M_{z d}(t) \\
& +\left(F_{y t f r}(.)-F_{y t f l}(.)\right) \sin \left(\delta_{f}(t)\right) t_{f} .
\end{aligned}\right.
$$

where the notations are as follows:

- $m=4 m_{s}+2 m_{u s f}+2 m_{u s r}$ : total vehicle mass, with $m_{s}: 1 / 4$ of the total sprung mass, $m_{u s f}: 1 / 2$ of the front unsprung mass, $m_{u s r}: 1 / 2$ of the rear unsprung mass,

- $I_{z}=I_{z s}+2 m_{u s f} l_{f}^{2}+2 m_{u s r} l_{r}^{2}:$ moment of inertia of the vehicle around the vertical axis with $I_{z s}$ : moment of inertia of the sprung mass around the vertical axis (in the sprung mass frame),

- $l_{f}\left(\right.$ resp. $\left.l_{r}\right)$ : distance from the front axle (resp. rear) to the center of gravity of the car, $t_{f}$ (resp. $t_{r}$ ) : distance from the wheel center to the axle center at the front (resp. rear),

- $F_{y t i j}($.$) : front and rear, left and right, lateral tire forces (i=\{f, r\}),(j=$ $\{r, l\}), F_{y d}(t)$ : lateral disturbance force, $M_{z d}(t)$ : disturbance moment of inertia around the vertical axis, 
- $\delta_{v}(t)$ : steering wheel angle, $\delta_{f}(t)$ : front steering angle,

- $\mathrm{C}$ : location of projection of the center of gravity of the vehicle to the ground,

- $v_{x}(t)$ (resp. $\left.v_{y}(t)\right)$ : longitudinal speed (resp. lateral) of $\mathrm{C}$ in the vehicle frame, $\beta(t)=\arctan \left(\frac{v_{y}(t)}{v_{x}(t)}\right)$ : vehicle attitude,

- $\dot{\psi}(t)$ : yaw rate,

- $a_{x}(t)$ (resp. $\left.a_{y}(t)\right)$ : longitudinal acceleration (resp. lateral) of $\mathrm{C}$ in the vehicle frame.

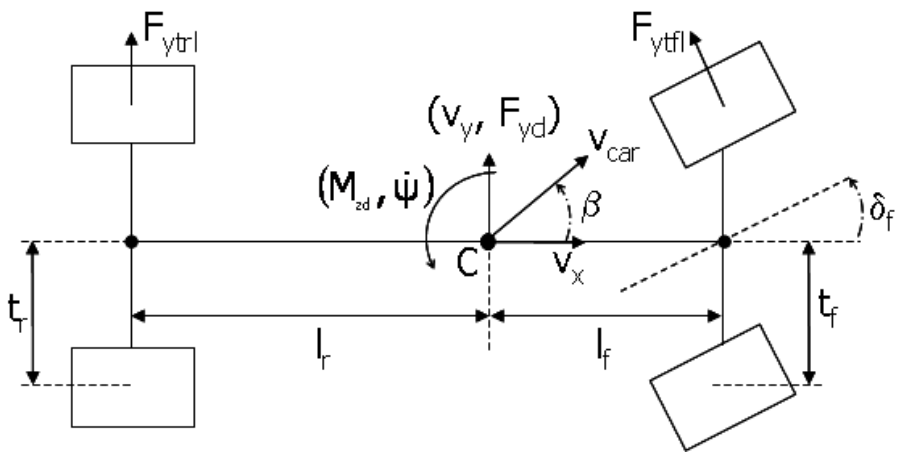

Figure 1 Horizontal car model

The tire lateral forces are calculated through the well known tire static model of Paceijka as below [16, 17, 13]:

$$
F_{y t i j}=D \cdot \sin \left(C \cdot \arctan \left(B \cdot \alpha_{i j}-E \cdot\left(B \cdot \alpha_{i j}-\arctan \left(B \cdot \alpha_{i j}\right)\right)\right)\right)
$$

where, $B, £ C, £ D$ and $E$ are function of the normal force $F_{z t i j}$ and the four wheel sideslip angles are given by:

$$
\left\{\begin{array}{l}
\alpha_{f r}(t)=\arctan \left(\frac{v_{y}(t)+l_{f} \dot{\psi}(t)}{v_{x}(t)+t_{f} \dot{\psi}(t)}\right)-\delta_{f}(t), \\
\alpha_{f l}(t)=\arctan \left(\frac{v_{y}(t)+l_{f} \dot{\psi}(t)}{v_{x}(t)-t_{f} \dot{\psi}(t)}\right)-\delta_{f}(t), \\
\alpha_{r r}(t)=\arctan \left(\frac{v_{y}(t)-l_{r} \dot{\psi}(t)}{v_{x}(t)+t_{r} \dot{\psi}(t)}\right) \\
\alpha_{r l}(t)=\arctan \left(\frac{v_{y}(t)-l_{r} \dot{\psi}(t)}{v_{x}(t)-t_{r} \dot{\psi}(t)}\right) .
\end{array}\right.
$$

The vertical tire forces $F_{z t i j}($.$) are therefore considered as exogenous model inputs$ and will be provided by the vertical model.

According to figure 2, the model exogenous inputs (1) are the disturbance forces and moments $F_{y d}(t), M_{z d}(t)$, and the vertical tire forces $F_{z t i j}($.$) , the steering wheel$ angle $\delta_{v}(t)$ given by the driver and the variation of the longitudinal speed $\dot{v}_{x}(t)$ (referred to as $v_{x} s t$ in the figure). 




Figure 2 Scheme of the horizontal dynamical model

On the other hand, the vertical model is given on figure 3, and satisfies:

(4)

$$
\left\{\begin{aligned}
4 m_{s} \ddot{z}_{s}(t)= & F_{s f r}(.)+F_{s f l}(.)+F_{s r r}(.) \\
& +F_{s r l}(.), \\
I_{x s} \ddot{\theta}(t)= & \left(-F_{s f r}(.)+F_{s f l}(.)\right) t_{f} \\
& +\left(-F_{s r r}(.)+F_{s r l}(.)\right) t_{r} \\
& +m H a_{y}(t), \\
I_{y s} \ddot{\phi}(t)= & \left(F_{s r r}(.)+F_{s r l}(.)\right) l_{r} \\
& -\left(F_{s f r}(.)+F_{s f l}(.)\right) l_{f} \\
& -m H a_{x}(t), \\
m_{u s i j} \ddot{z}_{u s i j}(t)= & -F_{s i j}(.)+F_{z t i j},
\end{aligned}\right.
$$

with:

- $I_{x s}$ (resp. $\left.I_{y s}\right):$ moment of inertia of the sprung mass around the longitudinal (resp. lateral) axis,

- $H$ : height of the center of gravity of the car,

- $z_{s}(t)$ : vertical displacement of CG,

- $\theta(t)$ : roll angle of the sprung mass,

- $\phi(t)$ : pitch angle of the sprung mass

In (4) $F_{s i j}($.$) is the vertical force delivered by the front/rear (i=\{f, r\})$ right/left $(j=\{r, l\})$ suspension.

Passive suspension : in this case

$$
F_{s i j}(.)=F_{k s i j}(.)+F_{c s i j}(.),
$$




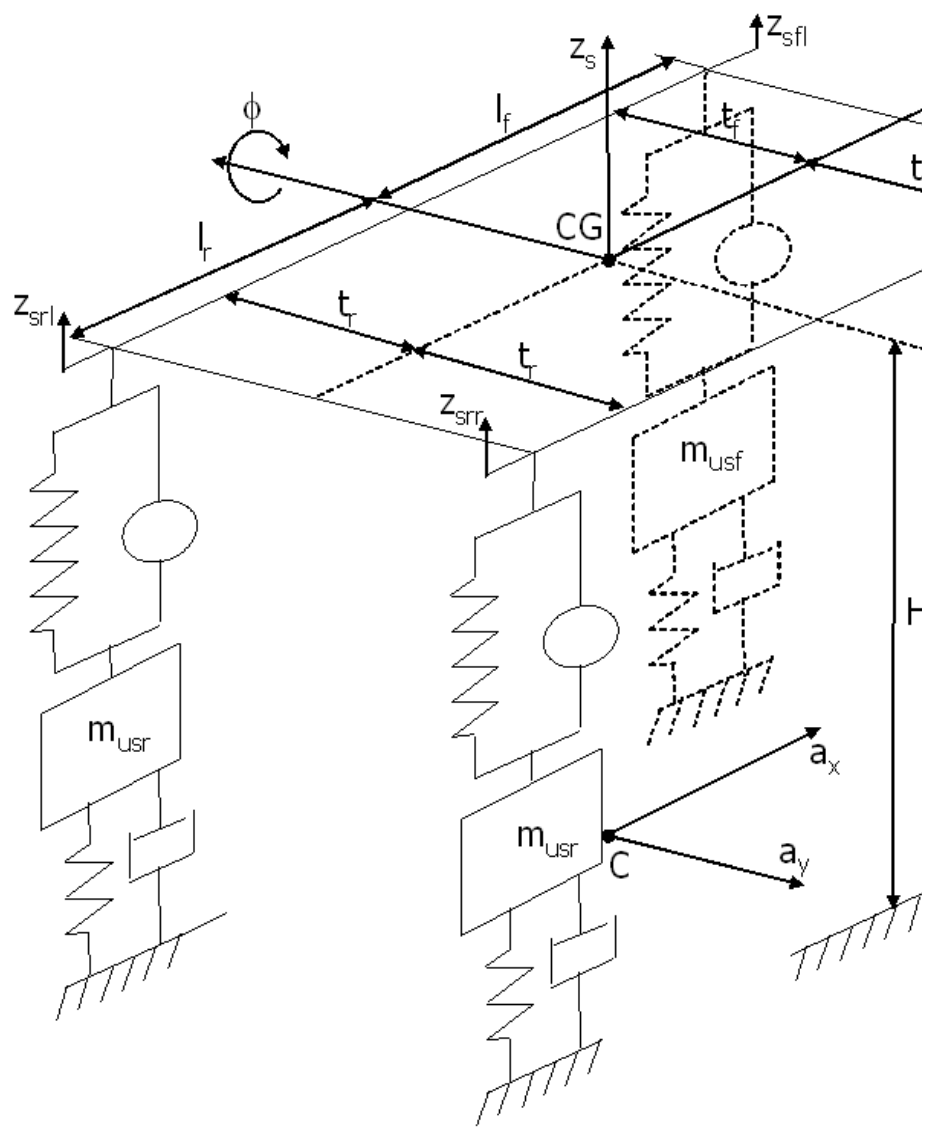

Figure 3 Vertical car model

where $F_{k s i j}($.$) and F_{c s i j}($.$) are nonlinear functions given by the static maps in$ figure 4 for the front and rear suspensions (spring and damper). This passive case is considered as the reference non-controlled case for comparison.

Active suspension: in this case

$$
F_{s i j}(.)=F_{k s i j}(.)+u_{c s i j}
$$

where $u_{c s i j}$ is the force provided by the active damper. It will be detailed in the next section.

The absolute position of the deflection $Z_{\text {defij }}(t)$, used in the static maps, is given by:

$$
Z_{\text {defij }}(t)=\left(Z_{s i j}-Z_{u s i j}+z_{s i j}(t)-z_{u s i j}(t)-l_{k s i j}\right),
$$

where $l_{k s i j}$ is the nominal spring length, $Z_{s i j}$ and $Z_{u s i j}$ are the absolute positions of the sprung and unsprung masses, respectively. These are calculated assuming 

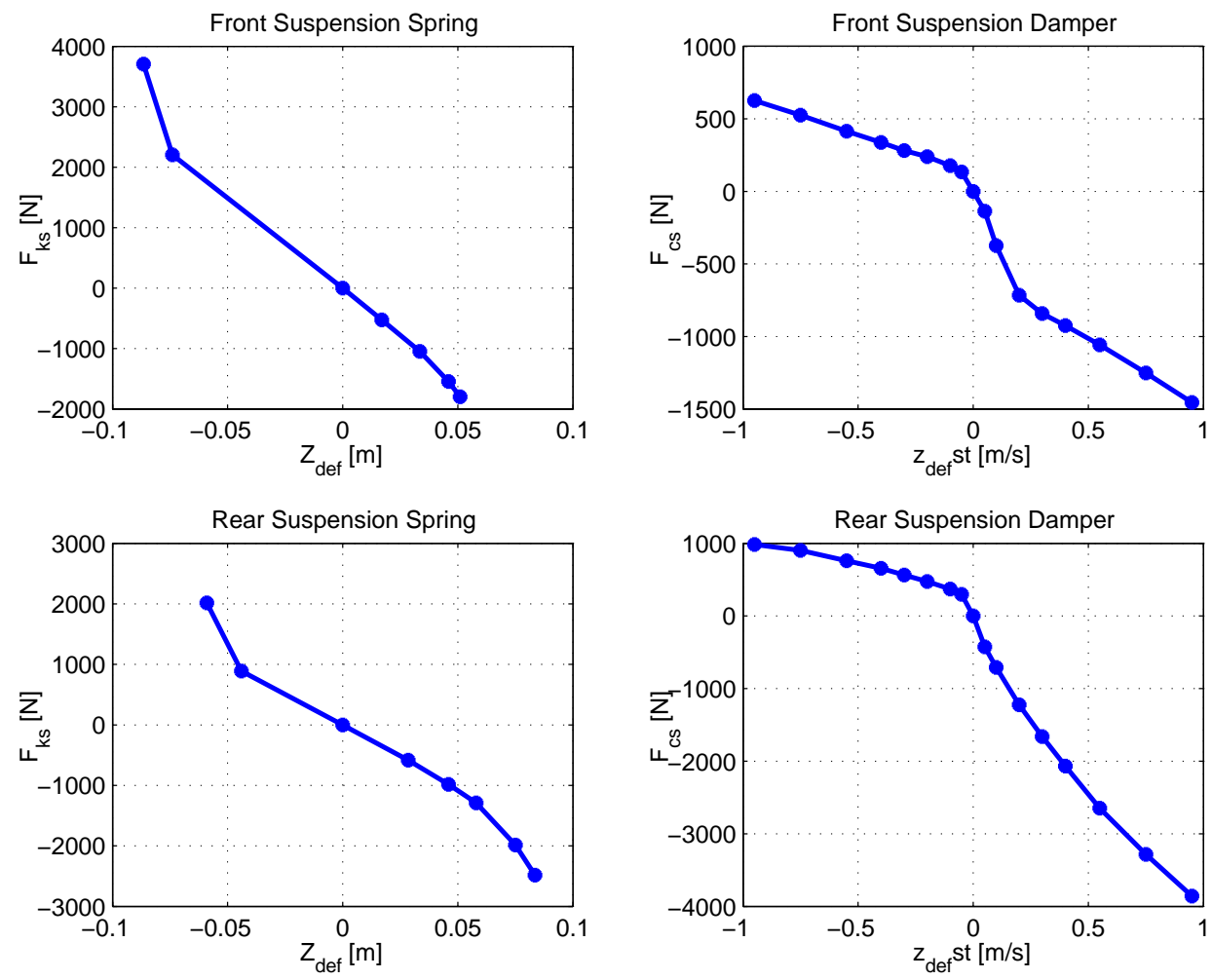

Figure 4 Non linear characteristics of the suspension forces.

$F_{z d}(t)=M_{x d}(t)=M_{y d}(t)=a_{x}(t)=a_{y}(t)=z_{0 i j}(t)=z_{s i j}(t)=z_{u s i j}(t)=0$ in $(4)$ and can be obtained, if necessary, by inversion of the characteristics $F_{k s}($.$) in figure$ 4, i.e. :

$$
\left\{\begin{array}{l}
\left(Z_{s}-Z_{u s}-l_{k s}\right)=F_{k s}^{-1}\left(F_{m s}^{0}\right) \\
\left(Z_{u s}-l_{k t}\right) \\
=-\frac{\left(F_{m s}^{0}+F_{m u s}^{0}\right)}{k_{t}} .
\end{array}\right.
$$

where $F_{m s}^{0}$ and $F_{m u s}^{0}$ are the static loads of $m_{s}$ and $m_{u s}$. Finally the deflection positions of the four suspensions are given by :

$$
\left\{\begin{array}{lll}
z_{s f r}(t)=z_{s}(t)-l_{f} & \sin \phi(t)-t_{f} & \sin \theta(t) \\
z_{s f l}(t)=z_{s}(t)-l_{f} & \sin \phi(t)+t_{f} & \sin \theta(t) \\
z_{s r r}(t)=z_{s}(t)+l_{r} & \sin \phi(t)-t_{r} & \sin \theta(t) \\
z_{s r l}(t)=z_{s}(t)+l_{r} & \sin \phi(t)+t_{r} & \sin \theta(t)
\end{array}\right.
$$

Moreover the vertical tire forces are calculated using eq. (9) and (10), i.e.

$$
F_{t}(.)=F_{k t}(.)+F_{c t}(.),
$$


where $F_{k t}($.$) and F_{c t}($.$) satisfy the following linear equations :$

$$
\left\{\begin{array}{l}
Z_{\text {deft }}(t)=\left(Z_{u s}-z_{u s}(t)+z_{0}(t)-l_{k t}\right), \\
\dot{z}_{\text {deft }}(t)=\left(\dot{z}_{u s}(t)-\dot{z}_{0}(t)\right) \\
F_{k t}(.)=-k_{t} Z_{\text {deft }}(t) \\
F_{c t}(.)=-c_{t} \dot{z}_{\text {deft }}(t) .
\end{array}\right.
$$

Following fig. 5, the exogenous inputs of the vertical model are the ground profile $z_{0 i j}(t)$, the longitudinal and lateral accelerations $a_{x}(t), a_{y}(t)$ of $\mathrm{C}$. The "Suspension characteristics" block includes, for the case of passive suspension, the force-deflection speed static map. For controlled suspensions, it corresponds to the controlled input forces (6).

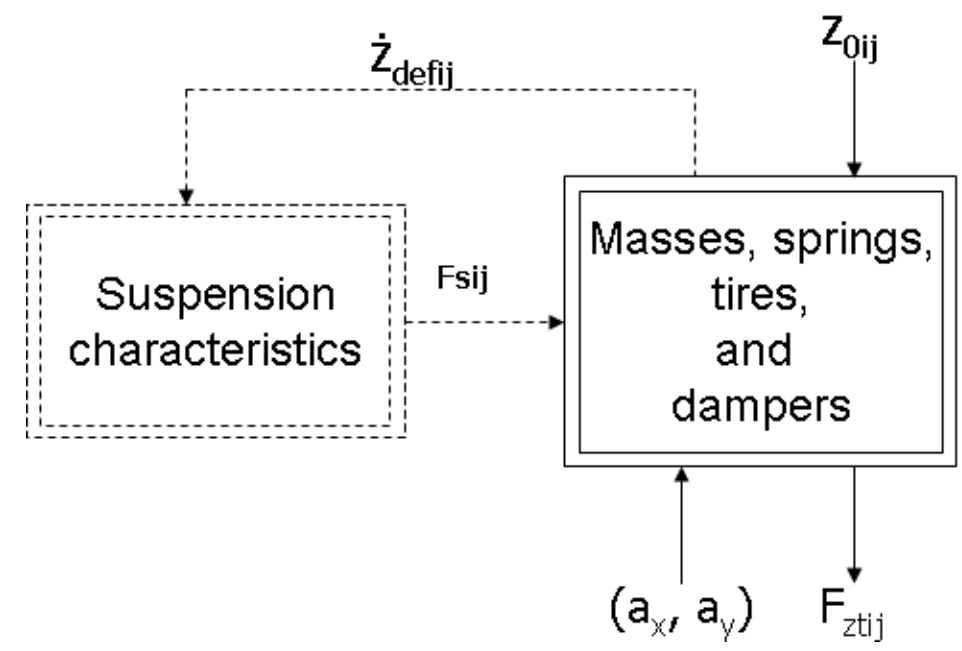

Figure 5 Scheme of the vertical model.

\section{An LPV feedback controller for active suspensions}

In this section, some results presented in [26] are briefly recalled. The objective is to design an $L P V / H_{\infty}$ controller scheduled according to the stiffness coefficient of the suspension spring $k_{s}($.$) in order to improve performance and robustness. The$ scheduled design controller is based on the $\mathcal{H}_{\infty}$ theory applied to polytopic systems. The theoretical results used for control design can be found in [1].

The control design step is carried out using a quarter-car model and then applied to each of the four suspension active dampers, as shwon in figure 6 .

\subsection{The suspension control-oriented model}

The control scheme is given in figure 7 . The signal $F_{m s}^{0}$ is the steady stade force caused by the weight of the sprung mass, which has to be known in order to evaluate the value of the steady state deflection $\left(Z_{s}-Z_{u s}-l_{k s}\right)$ in (7). This initial measure may be delivered by a pressure sensor installed in the active shock 

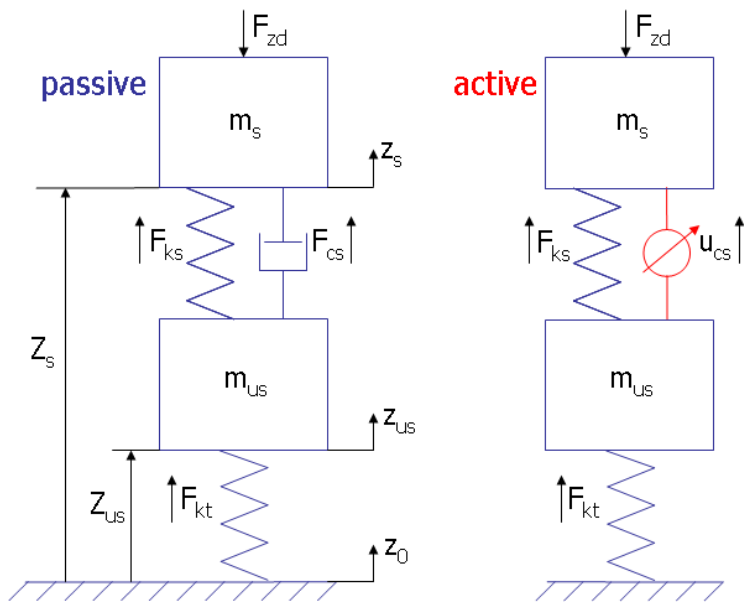

Figure 6 Quarter-car suspension models (passive and active).

absorber. Then it allows to get on-line the real-time value of $k_{s}($.$) used in figure 7$ for each damper, i.e.

$$
k_{s}\left(Z_{\text {defij }}\right)=-\frac{F_{k s}\left(Z_{\text {defij }}\right)}{Z_{\text {defij }}}
$$

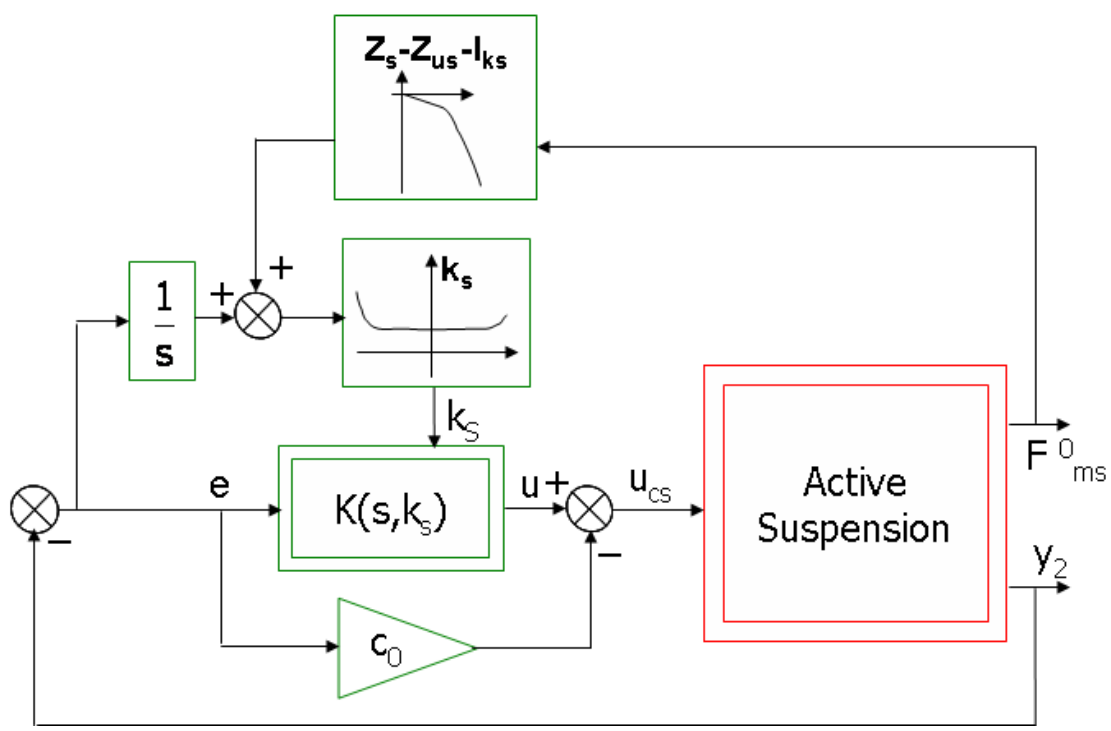

Figure 7 Scheme for the LPV design

The controller $K\left(s, k_{s}\right)$ is designed using the following LPV model where

$$
\dot{x}(t)=A_{a}\left(k_{s}\right) x(t)+B_{1} d(t)+B_{2} u(t),
$$

with 


$$
\begin{aligned}
x(t)^{T} & =\left[\dot{z}_{s}(t), z_{s}(t), \dot{z}_{u s}(t), z_{u s}(t)\right], \\
d(t)^{T} & =\left[F_{z d}(t), z_{0}(t)\right],
\end{aligned}
$$

where

$$
\begin{aligned}
& A_{a}\left(k_{s}\right)=\left[\begin{array}{cccc}
-\frac{c_{0}}{m_{s}}-\frac{k_{s}(.)}{m_{s}} & \frac{c_{0}}{m_{s}} & \frac{k_{s}(.)}{m_{s}} \\
1 & 0 & 0 & 0 \\
\frac{c_{0}}{m_{u s}} & \frac{k_{s}(.)}{m_{u s}} & -\frac{c_{0}}{m_{u s}}-\frac{\left(k_{s}(.)+k_{t}\right)}{m_{u s}} \\
0 & 0 & 1 & 0
\end{array}\right] \\
& B_{1}=\left[\begin{array}{cc}
-1 / m_{s} & 0 \\
0 & 0 \\
0 & k_{t} / m_{u s} \\
0 & 0
\end{array}\right], B_{2}=\left[\begin{array}{c}
1 / m_{s} \\
0 \\
1 / m_{u s} \\
0
\end{array}\right] .
\end{aligned}
$$

In this model, $c_{0}$ is a constant damping coefficient, while $k_{s}($.$) is a varying$ parameter. $c_{0}$ is here the nominal damping coefficient which could be chosen as the linear approximation of the damping. Then the control-oriented model uses $u_{c s}(t)=u(t)-c_{0} \dot{z}_{\text {deft }}(t)$ where $u$ corresponds to the variation of the damping force compared to the nominal passive suspension.

Therefore, assuming that $k_{s} \in\left[k_{s m}, k_{s M}\right]$ it can be consider as an affine model and can be rewritten as a polytopic model.

Remark 1: Note that in the following section, $c_{0}$ will be considered as a varying parameter.

The measurement $y(t)$ used for control design is the suspension deflection speed: $y(t)=\dot{z}_{u s}(t)-\dot{z}_{s}(t)$.

The controlled outputs are $z_{s}(t)$ and $u(t)$ and are sufficient to control the sprung masse acceleration $\ddot{z}_{s}(t)$, the suspension deflection $z_{d e f}(t)$ and the vertical displacement of the unsprung mass $z_{u s}(t)$.

\subsection{The $L P V / H_{\infty}$ suspension controller}

The performance specifications are as follows. For a fixed value of $c_{0}(t)$ and for all admissible values of the varying stiffness coefficient $k_{s}($.$) , the controller must$ improve the passenger comfort without deteriorating the vehicle road holding and the suspension deflection of the passive suspension for the same frozen damping value $c_{0}$.

As in the usual $\mathcal{H}_{\infty}$ framework, the performance objectives are achieved via minimizing weighted transfer function norms. The considered $L P V / \mathcal{H}_{\infty}$ control scheme is given in Fig. 8.

The $L P V / \mathcal{H}_{\infty}$ suboptimal control problem consists in designing a stabilizing controller $K\left(s, k_{s}\right)$ depending on the varying parameter $k_{s}($.$) that internally stabi-$ lizes the closed-loop system and minimizes a constant $\gamma$, s.t. the closed-loop transfer $\mathcal{H}_{\infty}$-norm between the exogenous inputs $w(t)$ to the exogenous outputs $e(t)$ is less or equal to $\gamma$ (i.e. $\left.\|e(t) / w(t)\|_{\infty} \leq \gamma\right)$ for any $k_{s} \in\left[k_{s m}, k_{s M}\right]$. 


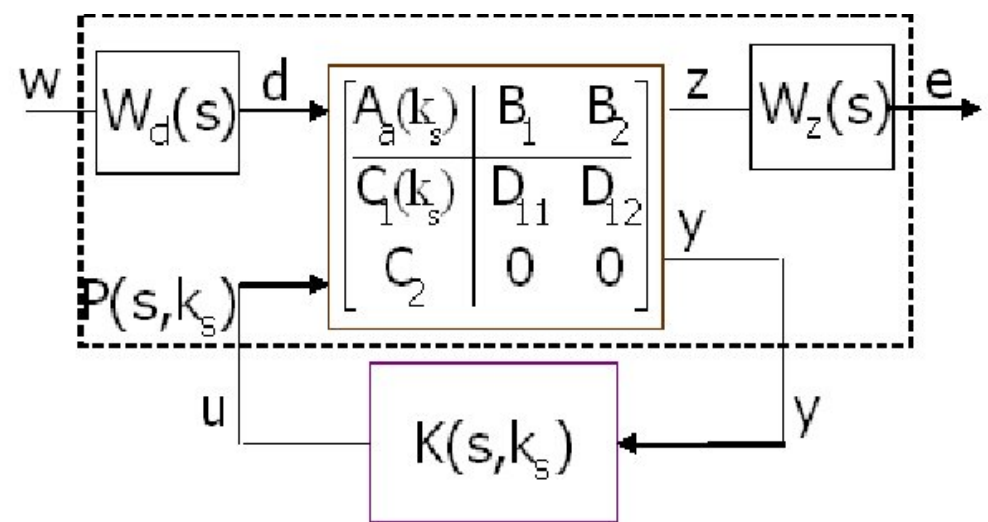

Figure $8 \quad L P V / \mathcal{H}_{\infty}$ control design interconnection.

The design method $L P V / H_{\infty}$ developed in [26] provides the results shown in figure 9 for $c_{0}=700 \mathrm{~N} / \mathrm{m} / \mathrm{s}$ where the frequency-domain behavior of the closedloop (i.e. active) system is compared to the open-loop (i.e. passive) one for the non linear model.
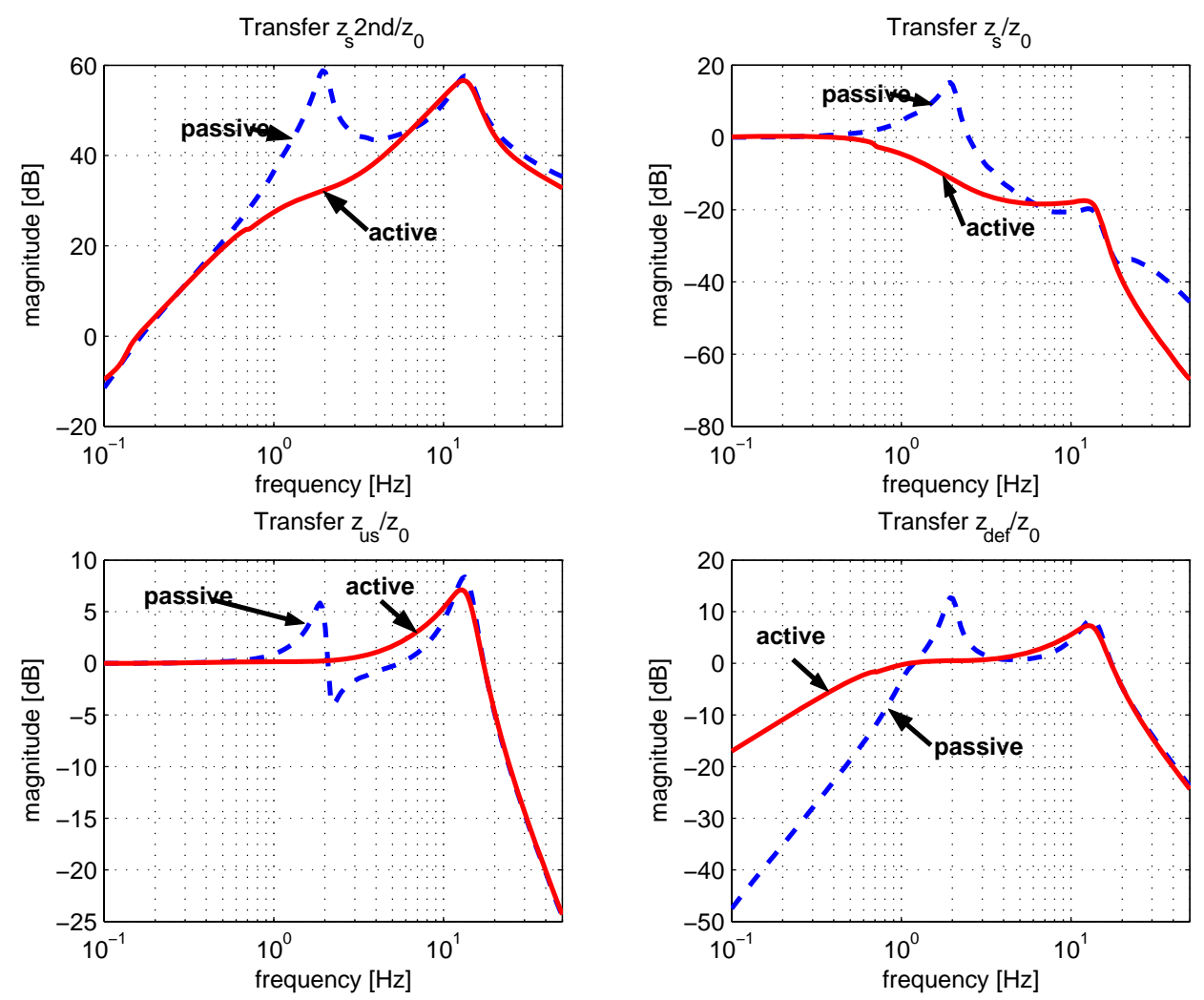

Figure 9 Non linear frequency-domain analysis of the active suspension using sinusoïdal input $z_{0}(t)$ and with $c_{0}(t)=700 \mathrm{~N} / \mathrm{m} / \mathrm{s}$. 
Remark 2: The "frequency" response of the nonlinear dynamical model is computed as follows: first, a finite set of pure sinusoïdal signals are chosen as being the road profile. The frequency of the sinusoids varies from 0.1 to $50.0 \mathrm{~Hz}$ with a constant amplitude of $0.015 \mathrm{~m}$. Then, at each frequency, $\ddot{z}_{s}(t), z_{s}(t), z_{u s}(t)$ and $z_{\text {def }}(t)$ are recorded. Finally, the frequency response of the nonlinear system is then computed as the input and output DFT magnitudes ratio.

As seen above, the driving comfort is improved between 0.5 and $5 \mathrm{~Hz}$ (see $\ddot{z}_{s}(s) / z_{0}(s)$ and $z_{s}(s) / z_{0}(s)$ in figure 9$)$ without deteriorating neither the road holding nor the suspension deflection compared to the passive case (see the transfer $z_{u s}(s) / z_{0}(s)$ and $\left.z_{\text {def }}(s) / z_{0}(s)\right)$.

However, it is well known that the drawback of road vibration isolation in suspension control leads to an amplification of the induced-oscillations due to load transfers for instance during a braking phase. In the next section, a feed-forward strategy is used to reduce these oscillations and to improve vehicle safety.

\subsection{About performance adaptation}

In the proposed design, $c_{0}(t)$ has been chosen constant in the design step, since the aim is to design a controller which improves the comfort while keeping the road holding as good as the passive suspension. The adaptation of the suspension characteristics is provided only by changing the value of $c_{0}$.

Indeed, for different frozen values of the parameter $c_{0}(t)$, the active suspension of the closed-loop model of Fig. 7 presents better performances than the passive model for the same frozen damping values (i.e. $c_{s}()=.c_{0}(t)$ ).

A comparison between the closed-loop frequency responses of the nonlinear passive and active systems is shown in Fig. 10 for $c(t)=\{700,2200,3700\} \mathrm{N} / \mathrm{m} / \mathrm{s}$ and when $k_{s}($.$) varies. The dash lines correspond to the passive model, the solid lines$ to the closed-loop active $L P V$ model. These values represent a hard, mid and soft suspension requirements, i.e. a road holding, deflection and confort objective. For each value of $c_{0}(t)$, the frequency responses of $\ddot{z}_{s}(t), z_{s}(t), z_{u s}(t), z_{\text {def }}(t)$, from $z_{0}(t)$, are plotted in order to evaluate the ability of the $L P V$ controller to improve the ride comfort, the road holding and the suspension stroke w.r.t the passive $L P V$ model.

It can be seen in Fig. 10 that for the same frozen value of the damping coefficient $c_{0}(t)$, the active suspension presents a better ride confort without deteriorating the road holding and the suspension deflection of the passive suspension. 0n the other hand, when the magnitude $c_{0}(t)$ decreases, the passenger comfort is increased, while the road holding is deteriorated (according to the trade-off between comfort/road holding [9]). Note also, that the peak of the transfer from the road profile $z_{0}(t)$ to the actuator forces $u_{c a}(t)$ does not increase when $c_{0}(t)$ increases, which of course is not the case of the $L P V$ control signal $u(t)$ (see Fig. 11).

This emphasizes the great intrinsic interest of using $c_{0}(t)$ as a varying coefficient in the controller. While allowing performance adaptation, neither the control structure does change nor the actuator frequency gain peak is increased. 

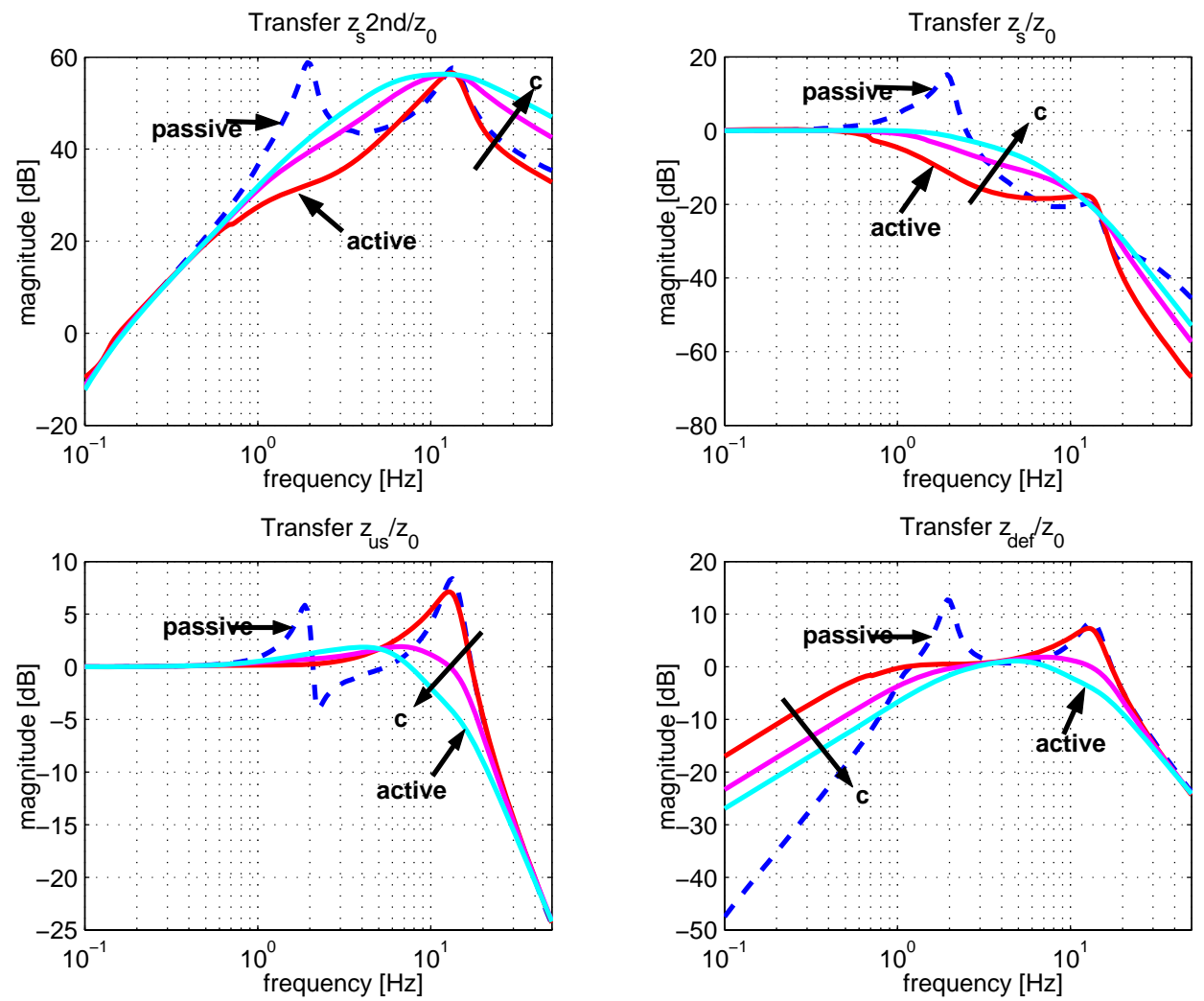

Figure $10 L P V / \mathcal{H}_{\infty}$ synthesis results in frequency domain for the closed loop model (with actuator) (solid line) and the passive model (dash line) for $c(t)=c_{s}()=$. $\{700,2200,3700\} \mathrm{N} / \mathrm{m} / \mathrm{s}$ and when $k s($.$) varies.$
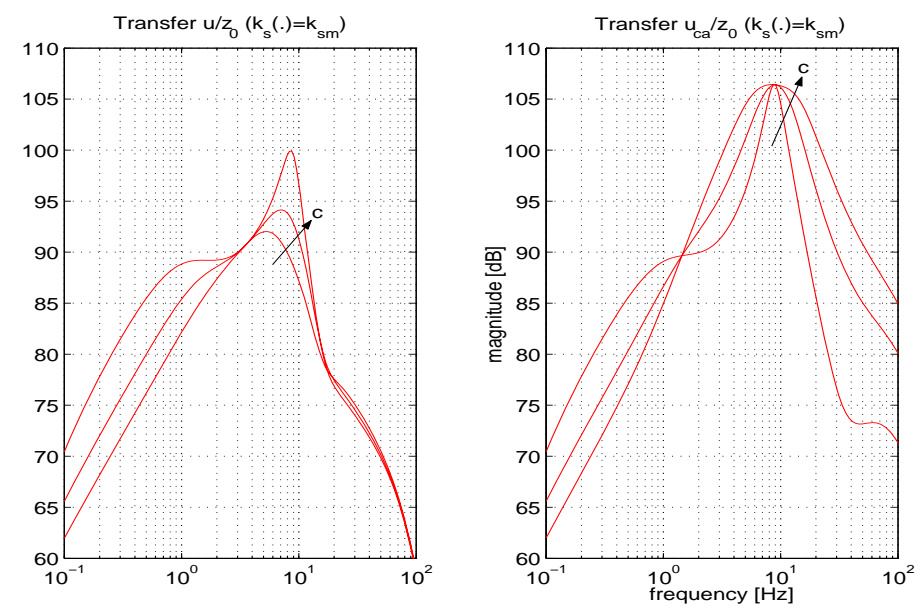

Figure 11 Active control input for $c(t)=\{700,2200,3700\} \mathrm{N} / \mathrm{m} / \mathrm{s}$. 
Remark 3 With reference to Fig. 4, a high value of the passive damping $c_{0}($.$) is$ obtained for low values (in magnitude) of the suspension velocity deflection. In fact, the damper characteristic of Fig. 4 is a typical static map of a "sporty" suspension setup: in low suspension deflection velocity (that is in general the framework of a suspension) the road holding is favoured. The trade-off between safety and comfort does not depend on the suspension deflection velocity, but on the stability of the vehicle. With the simple strategy presented in Fig. 7 the safety/comfort ability of a suspension can be changed online, depending on the stability of the vehicle.

\section{A feed-forward strategy for global chassis control through anti-roll distribution}

The need for feedforward control laws in vehicle dynamics control is today well known [11]. In this section a new strategy is proposed through an anti-roll distribution of the suspension forces in order to improve the comfort/safety trade-off.

First, the objective is to keep the sprung mass horizontal whatever the longitudinal and lateral vehicle accelerations are. It corresponds to require $\ddot{z}_{s}(t)=\ddot{\phi}(t)=$ $\ddot{\theta}(t)=0$, in the vertical dynamical equation system (4). If in (4) the forces $F_{s i j}($. are replaced by the feedforward signals to get $u_{f s i j}($.$) , they should satisfy:$

$$
\left\{\begin{aligned}
0= & u_{f s f r}(.)+u_{f s f l}(.)+u_{f s r r}(.)+u_{f s r l}(.), \\
0= & \left(\begin{array}{l}
\left.-u_{f s f r}(.)+u_{f s f l}(.)\right) t_{f}+ \\
\left.-u_{f s r r}(.)+u_{f s r l}(.)\right) t_{r}+m H a_{y}(t),
\end{array}\right. \\
0= & \begin{array}{l}
\left.u_{f s r r}(.)+u_{f s r l}(.)\right) l_{r}- \\
\left.u_{f s f r}(.)+u_{f s f l}(.)\right) l_{f}-m H a_{x}(t) .
\end{array}
\end{aligned}\right.
$$

The above system includes 3 equations for 4 unknown variables $u_{f s i j}($.$) . In order$ to ensure the existence of a unique solution, an equation dedicated to the anti-roll distribution is added. This distribution is represented by the scalar $\eta($.$) which corre-$ sponds to the anti-roll torque provided by the rear axle compared to the front axle, in order to compensate the induced-roll torque by $m H a_{y}(t)$. This is formulated below by the equation :

$$
(1-\eta(.))\left(u_{f s f l}(.)-u_{f s f r}(.)\right) t_{f}=\eta(.)\left(u_{f s r l}(.)-u_{f s r r}(.)\right) t_{r}
$$

\section{Remark 4}

- Note that, in real cars, this distribution is usually imposed by the anti-roll bars and by the suspensions themselves.

- With $\eta()=$.0 , the anti-roll behavior is obtained by the rear axle only (both forces $u_{f s f l}($.$) and u_{f s f r}($.$) equals); with \eta()=$.1 it is achieved by the front axle. 
From equations (13) and (14) the four feedforward forces become:

$$
\left\{\begin{array}{l}
u_{f s f r}(.)=-\frac{1}{2} H m\left(\frac{1}{l_{f}+l_{r}} a_{x}(t)-\frac{\eta(.)}{t_{f}} a_{y}(t)\right), \\
u_{f s f l}(.)=-\frac{1}{2} H m\left(\frac{1}{l_{f}+l_{r}} a_{x}(t)+\frac{\eta(.)}{t_{f}} a_{y}(t)\right), \\
u_{f s r r}(.)=-\frac{1}{2} H m\left(-\frac{1}{l_{f}+l_{r}} a_{x}(t)-\frac{1-\eta(.)}{t_{r}} a_{y}(t)\right), \\
u_{f s r l}(.)=-\frac{1}{2} H m\left(-\frac{1}{l_{f}+l_{r}} a_{x}(t)+\frac{1-\eta(.)}{t_{r}} a_{y}(t)\right) .
\end{array}\right.
$$

Since we wish to control $\eta(t)$ and $c_{0}$, we need to characterize the under and oversteering, hence to choose some "reference" vehicle. Here a "neutral" car is selected as a reference car.

\subsection{The reference car model}

The chosen reference car model is the well known bicycle model, i.e., the horizontal vehicle model (1), linearized around null steering wheel angle, and null tire sideslip angles. It is assumed that the left and right parts of the vehicle are symmetric. The model then satisfies the following equations:

$$
\left\{\begin{array}{l}
m a_{y}(t)=m\left(\dot{v}_{y}(t)+v_{x}(t) \dot{\psi}(t)\right)=2 F_{y t f}(.) \delta_{f}(t)+2 F_{y t r}(.) \\
I_{z} \ddot{\psi}(t)=2 F_{y t f}(.) \delta_{f}(t) l_{f}-2 F_{y t r}(.) l_{r} .
\end{array}\right.
$$

where $F_{y t f}($.$) and F_{y t r}($.$) are the front and rear lateral tire forces respectively.$ These are linear functions of the sideslip angles $\alpha_{i}$, i.e. $F_{y t i}()=.C_{\alpha_{i}} \alpha_{i}(t)$ with

$$
\left\{\begin{array}{l}
\alpha_{f}(t)=\arctan \frac{v_{y}(t)+l_{f} \dot{\psi}(t)}{v_{x}(t)}-\delta_{f}(t) \\
\alpha_{r}(t)=\arctan \frac{v_{y}(t)-l_{r} \dot{\psi}(t)}{v_{x}(t)}
\end{array}\right.
$$

where $C_{\alpha_{i}}$ are constant coefficients, obtained from the non linear tire characteristics (here we have chosen $C_{\alpha_{f}}=-8.4 \times 10^{4} \mathrm{~N} / \mathrm{rad}$ and $C_{\alpha_{r}}=-6.4 \times 10^{4} \mathrm{~N} / \mathrm{rad}$ ).

This model is an LPV model according to the longitudinal speed $v_{x}(t)$ but does not include any limitation of the attainable speed. Therefore the steering wheel angle is saturated in order to avoid too large lateral accelerations. The saturation bounds are calculated as the static gain of the transfer function from $\delta_{f}(t)$ to $a_{y}(t)$, paremetrized by $v_{x}(t)$, from equations $(15)$.

This concept is represented in figure 12 where the vehicle speed is $90 \mathrm{~km} / \mathrm{h}$, and where a bend is realized on a dry road considering a saturation of $a_{y}(t)$ at $10 \mathrm{~m} / \mathrm{s}^{2}$. The simulation results are represented in figure 12 and compared with the neutral car $(\eta=0.5)$. We can observe that the neutral reference car has no overshoot in $\dot{\psi}(t)$ and gives a linear characteristic for $\beta(t) / a_{y}(t)$.

\subsection{Yaw control through anti-roll distribution}

In this section, the previous reference model is used to derive a yaw control strategy by controlling the distribution $\eta($.$) , as shown in figure 13$. 

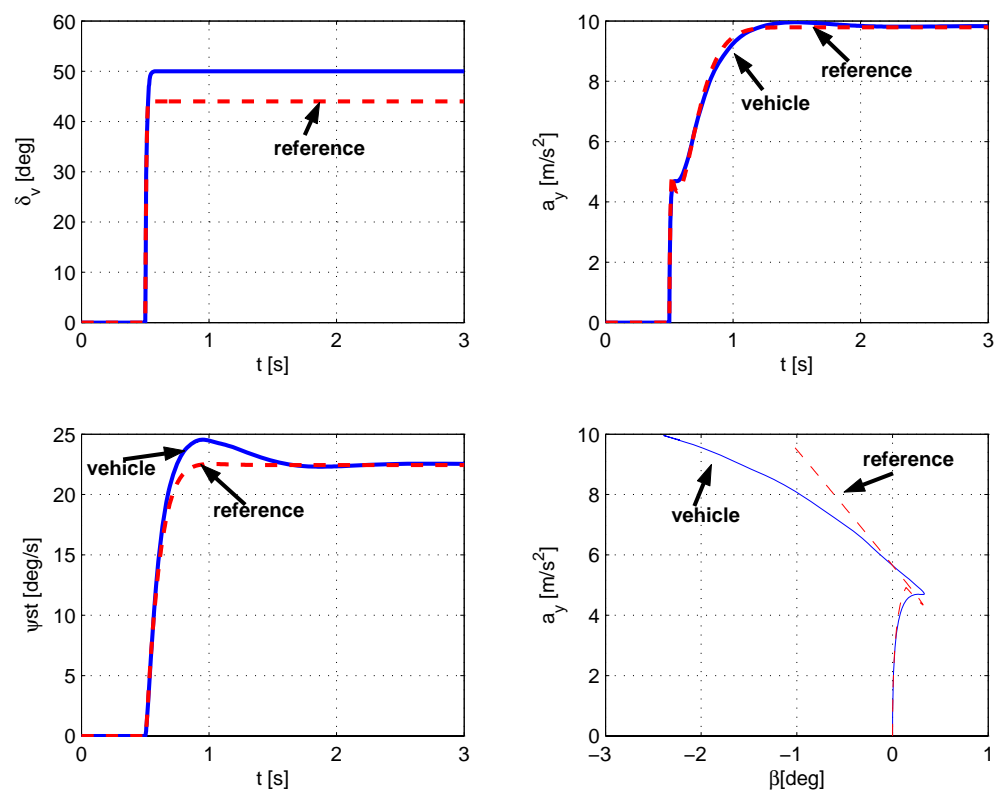

Figure 12 Reference model analysis.

The control objective is to reduce the error between the reference yaw rate and the measured one $\left(e_{\dot{\psi}(t)}=\dot{\psi}(t)-\dot{\psi}_{\text {ref }}(t)\right)$. The control input is the variation $\Delta_{\eta}($. of the parameter $\eta$ around its nominal value $\eta=0.5$. As $\Delta_{\eta}($.$) is between -0.5$ and 0.5 , a very simple PI controller with anti-windup is here chosen.

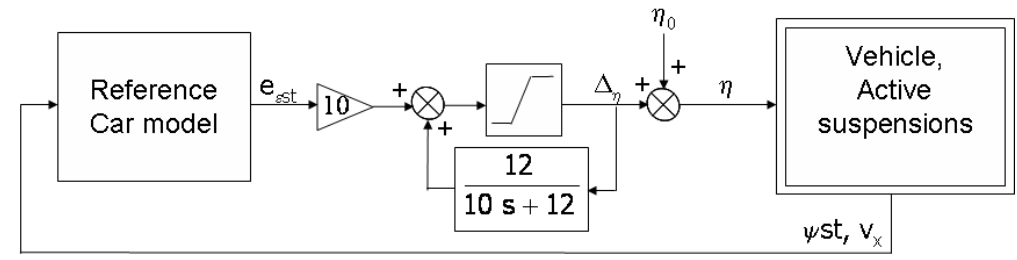

Figure 13 Yaw rate PI control strategy with anti-windup through anti-roll distribution.

To evaluate the performance of the global control scheme, the same manoeuver as in figure 12 is considered. As seen in figure 14, the overshoot is reduced thanks to the anti-roll distribution, and the response of the closed-loop system is faster than the one of the reference car (for which $\eta=0.5$ ). Of course there still exists some tracking error in the transient behavior but the use of anti-roll distribution greatly improves the yaw rate behavior (even if in this case the controlled vehicle is not completely neutral).

\subsection{Towards a global chassis control strategy}

In section 3, a $L P V / H_{\infty}$ controller has been designed for suspension control. In figure 7 , the given strategy includes the variation of the suspension stiffness coefficient $k_{s}$ and also, the parameter $c_{0}(t)$, which is considered constant during 

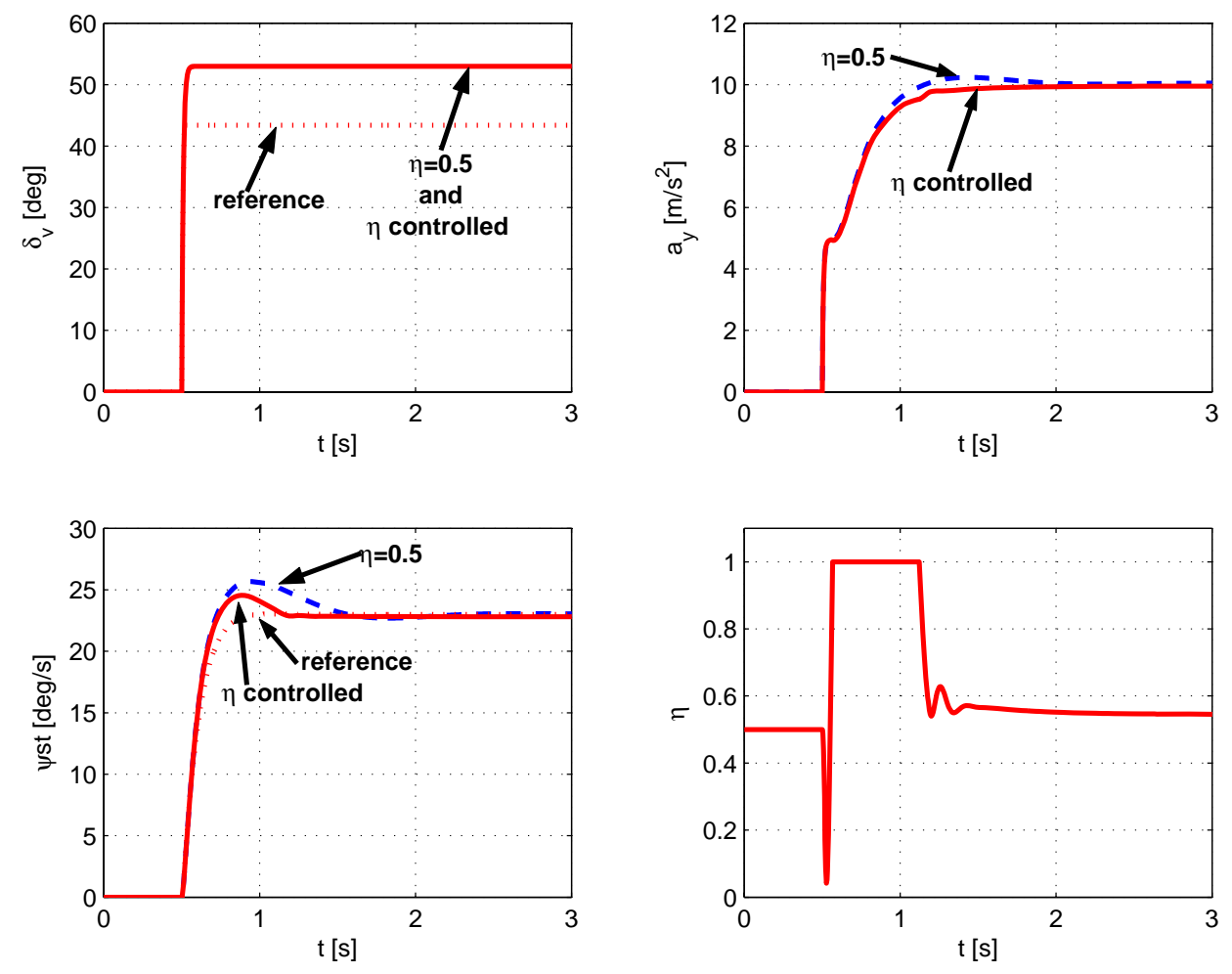

Figure 14 Simulation results of the yaw control strategy using anti-roll distribution

the design. On the other hand, the results in the previous section have shown that $\Delta_{\eta}($.$) represents the degree of understeering/oversteering of the vehicle.$

In order to increase the vehicle stability, the suspension will be made safety or comfort oriented according to the driving situations. As shown previously, the variation of the parameter $c_{0}(t)$ modifies the vertical dynamical performances, then it will be changed on-line, from $c_{0}()=.700 \mathrm{~N} / \mathrm{m} / \mathrm{s}$ (safety oriented), to $c_{0}()=$. $\mathrm{N} / \mathrm{m} / \mathrm{s}$ (comfort oriented). A very simple proportional controller is here proposed for validation.

For illustration, the same manoeuver as in figure 14 is simulated, for a random road profile. As seen in figure 15 , controlling $c_{0}$ greatly reduces the oscillations of the yaw rate, compared with the case where $\eta$ only is controlled. As seen in the right-lower figure, $c_{0}$ is varying according to $\eta$.

Figure 16 shows the time responses of the vertical dynamics. As expected, controlling $c_{0}$ deteriorates the vehicle comfort but in favour of the vehicle safety.

\section{Conclusions}

In this paper a new global chassis control strategy is developed using the suspension actuators only. First, a robust $H_{\infty}$ controller of the suspension is designed. Its inherent structure allows for performance adaptation through the variation of a coefficient $c_{0}$. Then, to improve the vehicle safety in the presence of longitu- 

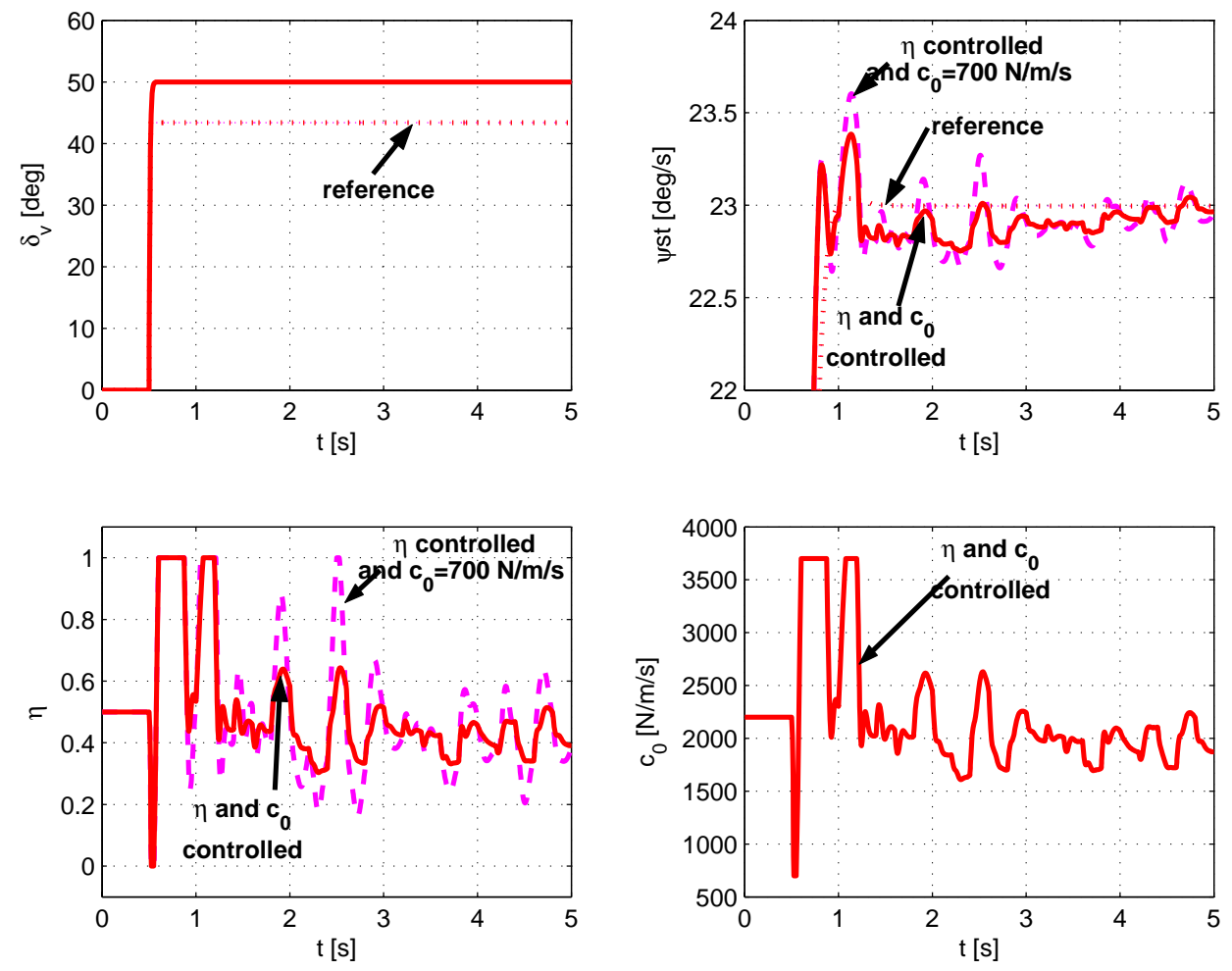

Figure 15 Global chassis control: analysis of the lateral dynamics.

dinal and lateral disturbances, a feedforward strategy is proposed, by controlling the anti-roll distribution of the suspension forces. The control scheme consists in controlling the yaw rate through a model reference control. The global chassis control then relies on the adaptation of the suspension performance (comfort/safety) according to the anti-roll distribution. This strategy needs sensors for suspension control (4 deflection sensors and the initial damping forces), acceleration sensors (longitudinal, lateral), a yaw sensor and steering wheel sensors. All these sensors are currently used now in automotive industry.

Some improvements may rely on the reference car model, which needs to adapt to road conditions (dry, wet, icy ...). Some issues may concern the estimation of the road adhesion to be used in this global chassis control (see for instance [22]).

\section{References}

[1] P. Apkarian, P. Gahinet, and G. Becker. Self scheduled $\mathcal{H}_{\infty}$ control of linear parameter-varying systems: a design method. Automatica, 31(9):1251-1261, 1995.

[2] M. Corno, S. Savaresi, M. Tanelli, and L. Fabbri. On optimal motorcycle braking. Control Engineering Practice, 16(6):644-657, 2008. 

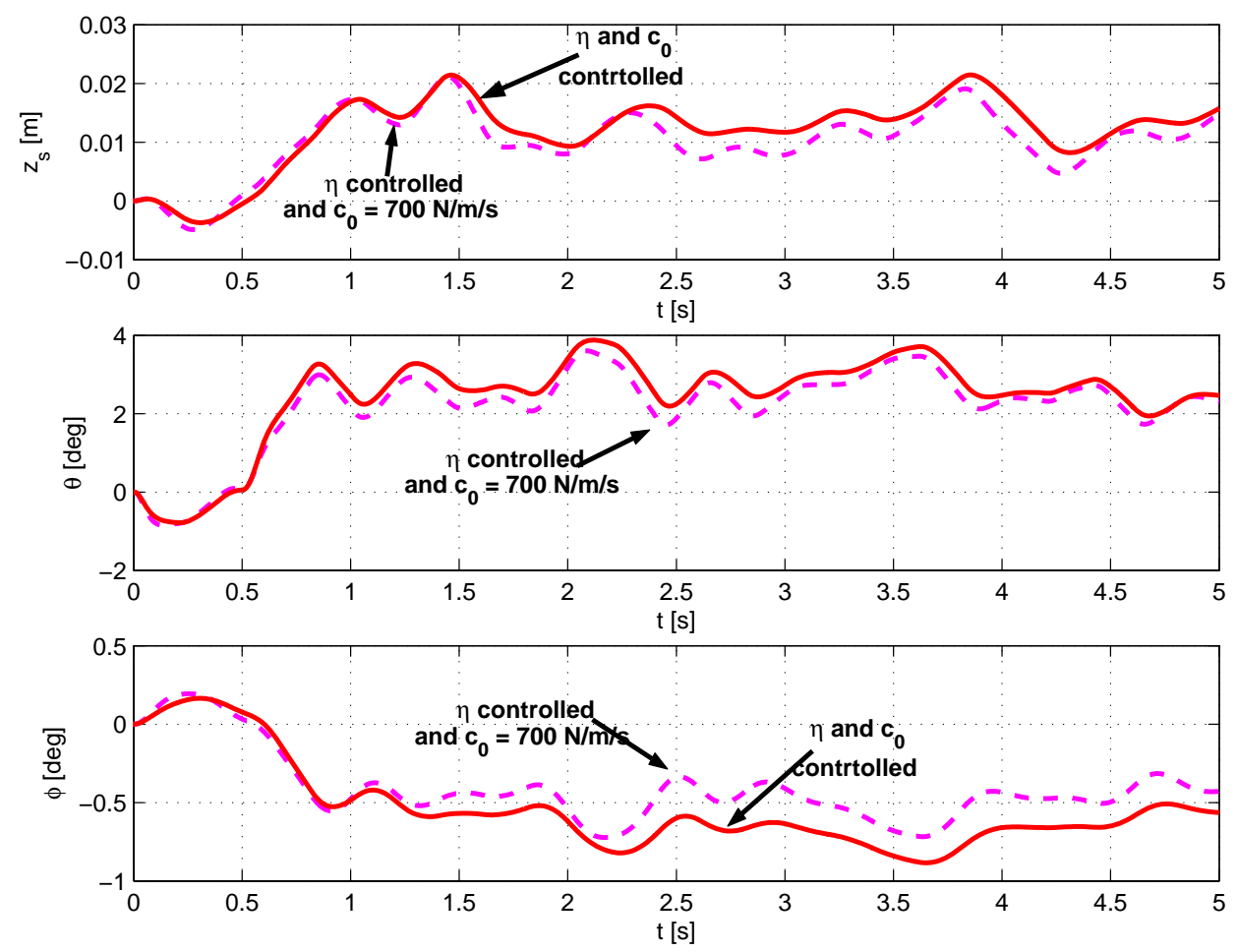

Figure 16 Global chassis control: analysis of the vertical dynamics.

[3] B. D'Andrea-Novel, H. Chou, and M. Pengov. Collaboration between braking torques and active suspension forces to control a vehicle. In European Control Conference ECC, Cambridge, UK, 1-4 sept. 2003.

[4] P. Gáspár and J. Bokor. A fault-tolerant rollover prevention system based on LPV method. International Journal of Vehicle Design, 2006.

[5] P. Gáspár, Z. Szabó, and J. Bokor. The design of an integrated control system in heavy vehicles based on an LPV method. In Proceedings of the $44^{\text {th }}$ IEEE Conference on Decision and Control (CDC), pages 6722-6727, Seville, Spain, december 2005.

[6] P. Gáspár, Z. Szabó, J. Bokor, C. Poussot-Vassal, O. Sename, and L. Dugard. Toward global chassis control by integrating the brake and suspension systems. In Proceedings of the $5^{\text {th }}$ IFAC Symposium on Advances in Automotive Control $(A A C)$, Aptos, California, USA, august 2007.

[7] P. Gaspar, I. Szaszi, and J. Bokor. Design of robust controllers for active vehicle suspension using the mixed $\mu$ synthesis. Vehicle System Dynamics, 40(4):193-228, 2003.

[8] P. Gaspar, I. Szaszi, and J. Bokor. The design of a combined control structure to prevent the rollover of heavy vehicle. European Journal of Control, 10(2):115,2004 . 
[9] J. K. Hedrick. Invariant properties of automotive suspensions. Journal of Automotive Engineering, 204(D):21-27, 1990.

[10] D. Hrovat. Survey of advanced suspension developments and related optimal control applications. Automatica, 33(10):1781-1817, 1997.

[11] S. Inagaki, H. Inoue, S. Sato, M. Tabata, and K. Kokubo. Development of feedforward control algorithms for active suspension. Society of Automotive Engineers, (920270), 1992.

[12] J. Lu and M. DePoyster. Multiobjective optimal suspension control to achieve integrated ride and handling performance. IEEE Transactions on Control Systems Technology, 10(6):807-820, 2002.

[13] W.F. Milliken and D.L. Milliken. Race car vehicle dynamics. SAE, 1995.

[14] C. Nouillant, F. Assadian, X. Moreau, and A. Oustaloup. Feedforward and CRONE feedback control strategies for automobile abs. Vehicle System Dynamics, 38(4):293-315, 2002.

[15] A. Oustaloup, X. Moreau, and M. Nouillant. The CRONE suspension. Control Eng. Practice, 4(8):1101-1108, 1996.

[16] H.B. Pacejka and E. Bakker. The magic formula tyre model. Vehicle Systems Dynamics, 21:1-18, 1993.

[17] H.B. Pacejka and I.J.M. Besselink. Magic formula tyre model with transient properties. Vehicle System Dynamics Supplement, 27:234-249, 1997.

[18] J. H. Park and Y. S. Kim. An $\mathcal{H}_{\infty}$ controller for active suspensions and its robustness based on a full car model. Proc. of the 14th IFAC, Beijing, (P-8b02-3):503-507, 1999.

[19] C. Poussot-Vassal, O. Sename, L. Dugard, P. Gáspár, Z. Szabó, and J. Bokor. Attitude and handling improvements through gain-scheduled suspensions and brakes control. In $17^{\text {th }}$ IFAC World Congress (WC), Seoul, South Korea, july 2008.

[20] D. Sammier, O. Sename, and L. Dugard. Skyhook and $\mathcal{H}_{\infty}$ control of semi-active suspensions: Some practical aspects. Vehicle System Dynamics, 39(4):279-308, 2003.

[21] Y. Shibahata. Progress and future direction of chassis control technology. In Proc. IFAC Symposium on Advances in Automotive Control, pages 9-14, Salerno, Italy, April 19-23, 2004.

[22] J. Stephant. Avaluation of sliding mode observer for vehicle sideslip angle. In 16th IFAC World Congress, Prague, Czech Rep., July 3-8 2005.

[23] E. Valtolina, S. Savaresi, S. Bittanti, A. Visconti, and A. Longhi. A co-ordinate approach for the control of road vehicles. In Proc. 6th European Control Conference, pages 629-634, Porto, Portugal, September 4-7 2001. 
[24] A. Zin, O. Sename, M. Basset, L. Dugard, and G. Gissinger. A nonlinear vehicle bicycle model for suspension and handling control studies. Proc. of IFAC Conference on Advances in Vehicle Control and Safety, Genova, Italy, pages 638-643, 2004.

[25] A. Zin, O. Sename, and L. Dugard. Active comfort and handling improvement with a "3D" bicycle model. In Proc. IFAC Symposium on Advances in Automotive Control, pages 638-643, Salerno, Italy, April 19-23, 2004.

[26] A. Zin, O. Sename, P. Gaspar, L. Dugard, and J.Bokor. An LPV $/ \mathcal{H}_{\infty}$ active suspension control for global chassis technology: Design and performance analysis. IEEE American Control Conference, ACC 2006, Minneapolis, USA, June 14-16, 2006. 